\title{
Mini Mental State Examination and the Addenbrooke's Cognitive Examination: Effect of education and norms for a multicultural population
}

\author{
P. S. Mathuranath, Joseph P. Cherian, Robert Mathew, Annamma George, Aley Alexander, \\ Sankara P. Sarma* \\ Cognition and Behavioral Neurology Center, Department of Neurology, Sree Chitra Tirunal Institute for Medical Sciences and \\ Technology (SCTIMST), Trivandrum, Kerala, *Department of Biostatistics and Epidemiology, Achutha Menon Center for Health Science \\ Studies, Trivandrum, Kerala, India
}

Objective: To derive population norms on the Malayalam adaptation of Addenbrooke's Cognitive Examination (M$\mathrm{ACE})$ and the inclusive Malayalam mini mental state examination (M-MMSE). Materials and Methods: Education-stratified norms were obtained on randomly selected cognitively unimpaired community elders $(\mathrm{n}=$ 519). Results: Valid data on norms was available on 488 subjects (age $68.5 \pm 7.1$ and education $7.9 \pm 5.4$ ). Education and age, but not gender had a significant effect on both $M$ ACE and M-MMSE. When compared to the effect of age, the effect of education was sevenfold more on the M-ACE and ninefold more on the M-MMSE. The mean composite score on the M-ACE (and the M-MMSE) was $42.8 \pm 9.8$ (14.9 \pm 3.1) for those with $0(n=72), 55.9 \pm 12.5(19.7 \pm 4.1)$ with 1 $4(\mathrm{n}=96), 62.6 \pm 11.4(21.9 \pm 3.7)$ with $5-8(\mathrm{n}=81), 77 \pm$ $10.2(25.7 \pm 2.4)$ with $9-12(n=136)$ and $83.4 \pm 7.2(26.7 \pm$ $1.6)$ with $>12(n=103)$ years of formal education. Conclusions: Education has the most potent effect on performance on both M-ACE and M-MMSE in the Indian cohort. Education-stratified scores on the M-ACE and the M-MMSE, will provide a more appropriate means of establishing the cognitive status of patients. It is also our feeling that these cut-off scores will be useful across India.

Key words: Addenbrooke's cognitive examination, dementia, developing countries, elderly, mini mental status examination, scale, screening

Screening for early dementia in epidemiological studies requires a sensitive assessment of cognition and the abilities to carry out social and occupational functions. Objective assessment of the former is done using global cognitive screening scales and that of the latter using functional activities tools. In the first of a two-phase (screening and evaluation) epidemiological study for dementia in the southern Indian state of Kerala, we intend to screen for dementia using a combination of a cognitive screening and a functional activities assessment tool. Our first task in this direction was to develop tools valid for the local population.

Since we already had some experience of using the Addenbrooke's cognitive examination (ACE), ${ }^{[1]}$ on our population, we chose this global cognition screening battery as our cognition screening tool. The ACE is similar in its design to the neuropsychological battery of the consortium to establish a registry for Alzheimer's disease $(C E R A D)^{[2]}$ for diagnosing dementia. It helps differentiate early Alzheimer's disease (AD) from frontotemporal lobar degeneration (FTLD), ${ }^{[1]}$ is reliable and sensitive for early dementia ${ }^{[1,3]}$ and has been successfully adapted in other languages. ${ }^{[4]}$ Earlier we have published the adaptation of the ACE into the local language, Malayalam (M-ACE). ${ }^{[5]}$ Like the ACE, the M-ACE incorporates the (Malayalam adaptation of the) mini-mental-state-examination (M-MMSE) in addition to having tests for orientation, attention, memory (immediate and delayed), remote memory, verbal fluency (initial letter |pa | in Malayalam and categories of animals), confrontation naming (10-items), reading, repetition, writing, executive functions (clock-drawing $)^{[6]}$ and constructional praxis (copying a line-drawing). The major changes to the M-ACE included exclusion of spelling "WORLD" backwards test; including seven words of local relevance in the address recall test; in naming test, replacing linedrawings of windmill, kangaroo and barrel with those of sickle, zebra and candle; and in repetition test, replacing the words in the ACE (including the irregular words) 
with regular Malayalam words of comparable frequency and word-length (as there are no irregular words in Malayalam). We have shown earlier that in its structure and content the M-ACE is equivalent to the ACE and has a comparable relative difficulty on the items. ${ }^{[5]}$

Although the MMSE is a widely used test in many parts of the developing world including India, only a few investigators have made culturally appropriate modifications to it before using it on the local population ${ }^{[7,8]}$ and fewer still use norms derived from and relevant to the local population. ${ }^{[9]}$ Using cognitive tests without appropriate culturally relevant adaptations and applying the norms derived largely from the western population has been widely recognized to result in overestimation of cognitive impairment in the local populations in the developing regions. ${ }^{[10]}$ The objective of this study, therefore, is to derive population-based norms on the MACE and the M-MMSE for use in the intended epidemiological study population in particular and in the Indian population, in general.

\section{Materials and Methods}

Norms were derived from 519 randomly selected community-based elders, living within the corporation limits of Trivandrum (Census 1991). ${ }^{[11]}$ This cohort was diverse in its demographic distribution and was comparable to the target population for our intended epidemiological study. Men constituted 37.5\% (vs. $41 \%$ in the target population), Hindus $70.3 \%$ (vs. 69.8\%), Christians 24.1\% (vs. 24.4\%), Muslims 5.6\% (vs. 5.8\%), $<75$ years of age $76.3 \%$ (vs. $76.9 \%$ ), subjects with $\leq$ four years of formal education $51 \%$ (vs. $31.4 \%$ ), monthly household incomes $\leq 1000$ Indian National Rupees (Rs.) $(\sim 22$ US \$) $31.2 \%$ (vs. 35\%) and $\geq$ Rs. 10001 ( $\geq 223$ US \$) $1.9 \%$ (vs. $2 \%$ ). Work types included unskilled laborers $11 \%$ (vs.12.4\%), clerks or vocational practitioners $28.5 \%$ (vs. $29.2 \%$ ), professionals $11.2 \%$ (vs. $14.8 \%$ ) and housewives $47.8 \%$ (vs. $43.6 \%$ ).

We have shown earlier that the level of education significantly affected the M-ACE composite score in our population ${ }^{[5]}$ Number of years of education was stratified based on the system prevalent at the time this elderly population received their education. Thus the groups were: 0 years (i.e., no formal education; $n=72$ ), 1-4 (primary education; $\mathrm{n}=96$ ), 5-8 (middle school; $\mathrm{n}=$ 81), 9-12 (high school/college; $\mathrm{n}=136$ ) and $>12$ (university; $\mathrm{n}=103$ ) years. For the purpose of analysis, age was stratified into 55-64 $(\mathrm{n}=162), 65-74(\mathrm{n}=218)$ and $\geq 75(\mathrm{n}=108)$ years.

All participants received a structured questionnaire and a semi-structured neurological and psychiatric evaluation to rule out a history or the presence of any alcoholism, head injuries, neurological diseases (epilepsy, strokes/TIAs, dementia and chronic headaches), cognitive impairment or major psychosis. Seven subjects refused participation, five had significant visual or hearing impairment, nine were suspected to have dementia or stroke, six were bedridden and physically too ill to participate and four were no longer residing at the address available on our database. The remaining 488 subjects (mean age $=68.5 \pm 7.1$; education $=7.9 \pm 5.4$; males $=194$ ) received the $\mathrm{M}$ ACE. As in other studies, nonresponse on any item was scored as zero. ${ }^{[12]}$

\section{Statistical analysis}

The magnitude of the effect of age, education and gender and their possible interactions (as the independent factors) on the composite M-ACE and the M-MMSE scores (as the dependent factors) were evaluated using univariate ANOVA and the direction of the effects was analyzed using linear regression. Means, standard deviations and $5^{\text {th }}, 10^{\text {th }}$ and $20^{\text {th }}$ percentiles (\%ile) were calculated for norms.

\section{Results}

\section{Effects of age, education and gender}

The main effects of education and age and the education* gender interaction were significant for both the M-ACE and the M-MMSE composite scores [Table 1]. Education (main effect) explained $23.7 \%$ and $22.4 \%$, age (main affect) $5.1 \%$ and $3.7 \%$ and education* gender (interaction) $<2 \%$ of the variance in the M-ACE and the M-MMSE composite scores respectively. Compared to age, education had a sevenfold greater effect on the M-ACE and a ninefold greater effect on the M-MMSE. While education had a direct association with both the scores, age had an inverse association. The size of the effects in

\begin{tabular}{|c|c|c|c|c|c|c|c|c|c|}
\hline & & \multicolumn{4}{|c|}{ ANOVA } & \multicolumn{4}{|c|}{ Regression } \\
\hline & & Mean Sq. & df & $\mathbf{F}$ & $P$ & $\bar{B}$ & SB & $95 \% \mathrm{Cl}$ for $\mathrm{B}$ & $P$ \\
\hline \multirow[t]{4}{*}{ M-ACE } & Education & 1675.29 & 21 & 17.56 & $\leq 0.001$ & 2.5 & 0.77 & 2.3 to 2.7 & $\leq 0.001$ \\
\hline & Age & 229.97 & 33 & 2.41 & $\leq 0.001$ & -0.38 & -0.16 & -0.52 to -0.26 & $\leq 0.001$ \\
\hline & Gender & 151.11 & 1 & 1.59 & 0.76 & -0.05 & - & - & 0.07 \\
\hline & Error & 95.42 & 196 & - & - & - & - & - & - \\
\hline \multirow[t]{4}{*}{ M-MMSE } & Education & 129.51 & 21 & 17.06 & $\leq .001$ & 0.71 & 0.76 & 0.66 to 0.76 & $\leq 0.001$ \\
\hline & Age & 14.31 & 33 & 1.89 & 0.018 & -0.08 & -0.11 & -0.12 to -0.04 & $\leq 0.001$ \\
\hline & Gender & 5.44 & 1 & 0.72 & 0.89 & -0.038 & - & - & 0.86 \\
\hline & Error & 7.59 & 196 & - & - & - & - & - & - \\
\hline
\end{tabular}


these results prompted us to opt for education-stratified cutoff scores for both, the M-ACE and the M-MMSE.

\section{Norms}

The average time to complete the M-ACE was 16 minutes. Table 2 shows the overall and education-stratified demographic data, the M-ACE composite and subscores and the M-MMSE scores on the 488 cognitively unimpaired subjects. There were no inter-group differences in age in the three groups with $\leq 8$ years of education or in the two groups with $\geq 9$ years of education. However, the groups with $\leq 8$ years of education were significantly older than those with $\geq 9$ years of education $(P<0.05)$. Figure 1 shows the distribution of the means with a $95 \%$ CI for the composite score and the various subscores of the M-ACE across the education-stratified groups. It shows a clear increase in the means on the various subscores as well as the composite score as education improves. It also shows that on nearly all the subtests of the M-ACE, the performance of the two groups with $\geq 9$ years of education was comparable, but better than that of the two groups with education between one and eight years. Again the performance of the 1-4 and 58 years groups were comparable, but distinctly better than the group with 0 years of education. Furthermore, except for the visuospatial subtest on which the 0 years education group showed floor effect, on none of the other subtests was such an effect seen in any of the education groups.

\section{Discussion}

The ACE offers the advantage of being a reliable and comprehensive neuropsychological battery, similar to the
CERAD neuropsychological battery. ${ }^{[1,5]}$ As detailed in our earlier report, ${ }^{[5]}$ the M-ACE, a Malayalam adaptation of the ACE, is similar to the ACE in its structure and equivalent to it, when used on the Indian population, on the degree and the rank order of difficulty of the various test items. It also carries the advantage of having the MMSE, which is a widely used cognitive test across the world.

To the best of our knowledge, this is the first report which has systematically studied the effects of relevant demographic factors on the MMSE score, showed education to have the most potent influence on it and then derived education-stratified population-based Indian norms on the MMSE.

The population-based norms were derived from a large number of randomly selected community-based elders. As highlighted in the methods, this was a heterogeneous population and included people from different religious, social and economic backgrounds and with varied educational abilities. Furthermore, as shown by the percentage distribution across various demographic characteristics, this cohort was qualitatively and quantitatively similar to that of the target population for whom the M-ACE was developed. Thus it provided an ideal cohort to derive the population-based norms.

In an earlier study with a smaller cohort we had found that education was the most important demographic factor that affected the M-ACE scores. ${ }^{[5]}$ The results of the present study validated this finding on a large, randomly selected, demographically heterogeneous cohort. Education continued to remain the only factor with a large and significant effect on the M-ACE and the M-MMSE scores. While it would be ideal to have the norms of cognitive batteries based on both education and age (and

Table 2: The demography and education-stratified scores and sub scores (mean (standard deviation)) of the norms cohort $(n=488)$

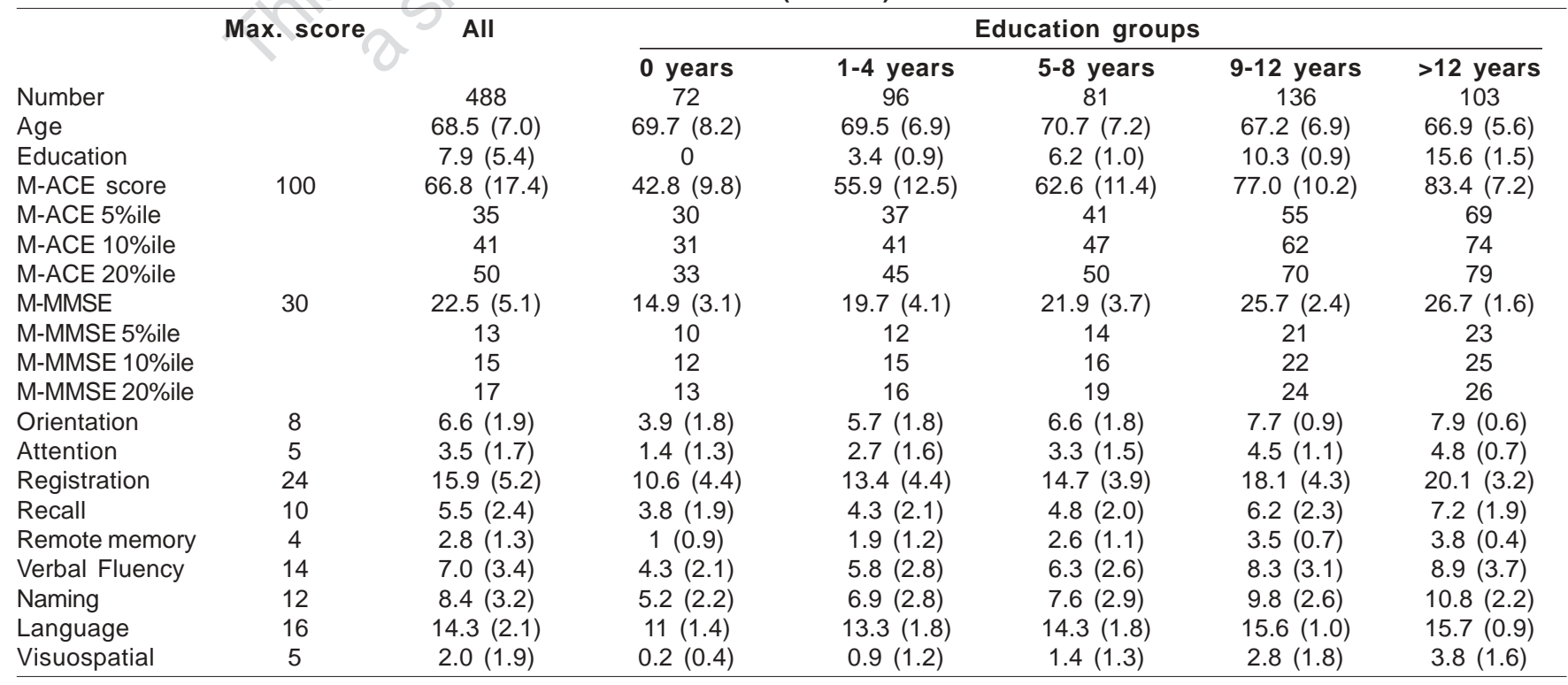

Max.: Maximum, M-ACE: Malayalam Addenbrooke's cognitive examination, M-MMSE: Malayalam mini mental state examination, \%ile: Percentile 

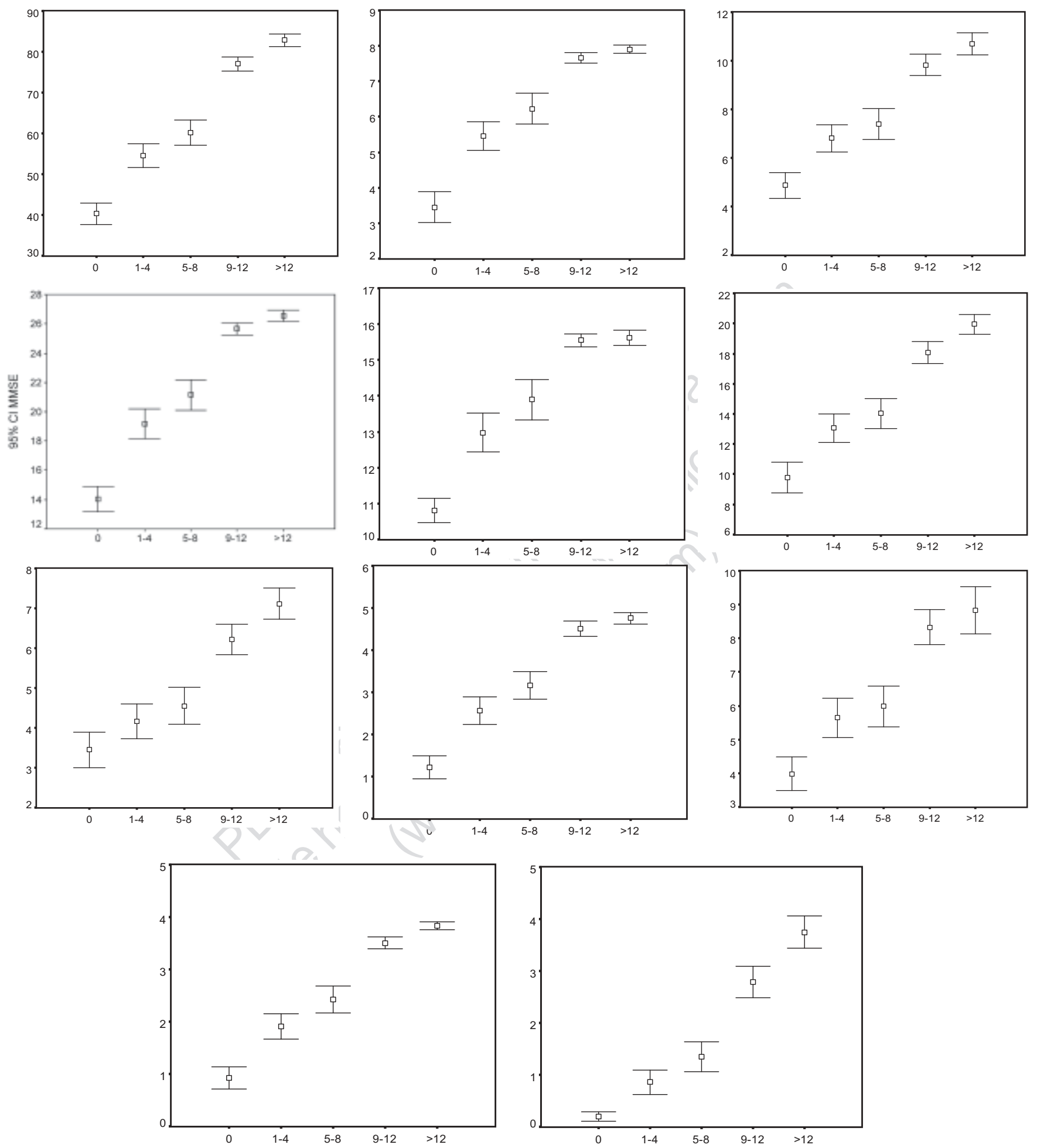

Figure 1: Error-bars showing the mean and its $95 \% \mathrm{Cl}$ for the education-stratified groups (X-axis) on the M-MMSE, M-ACE and its various components

if possible gender too), such norms would be extremely cumbersome to use and of little operation utility for screening purposes in epidemiological studies. Furthermore, since in comparison to education, the effects of age and gender were either small ( $<6 \%$ of total variance) or not significant, we opted for norms stratified on the basis of education.

It must be emphasized that with a mean age of 68.5 years, our cohort of elders largely comprised young olds (55-74 years). The fraction of old olds ( $\geq 75$ years) was relatively low, reflecting the age distribution in Kerala where they constitute only about $16 \%$ of the elders. ${ }^{[11]}$ 
As the mean age of the elderly population advances there will be a need to re-explore the effect-size of age on the performance on cognitive tests and to reevaluate the necessity for age-stratified cutoff scores on these cognitionscreening tests. In this context, one of the results of this study, which suggested that age indeed has a significant, albeit small, effect on the M-ACE and the M-MMSE scores, becomes relevant.

Although the way education was stratified in this study was arbitrary, the rationale behind it was the education levels prevailing at the time these elders, who form the target population of our intended survey, received their education. It was also guided by our own experience of over four years with these subjects on various neuropsychological tests. This study revealed that there were significant differences in the scores on the various subtests of the M-ACE between the different education groups. On nearly all the subtests of the M-ACE, the performance of the different education groups was gradedthat of the 9-12 and >12 years being better than that of 14 and 5-8 years groups which in turn was better than that of 0 years group. Though expected, these results ratify our rationale for choosing the levels used in the stratification. They also provide justification for clubbing some of the current groups and reducing the total number of groups, a situation that can offer more operational convenience in epidemiological surveys. On the tests evaluating visuospatial skills, an important cognitive domain, though the 0 years education group shows a flooring effect, the other education groups show a graded performance justifying the retention of this test in the MACE battery, as has been detailed elsewhere. ${ }^{[5]}$ This study also confirmed our earlier finding that on none of the tests assessing the functions of other domains is there a flooring effect seen with any of the education groups, ${ }^{[5]}$ thus making the M-ACE a useful battery for the local population.

We would like to emphasize that the results of this study are from a particular region of south India that has a better literacy and living standards than many other developing regions of India as well as the world. Although we feel that these cutoff scores are likely to be valid in most urban, semi-urban and perhaps even rural populations within India, we feel that caution must be exercised in extrapolating these results to communities with demographic and cultural profiles different from that in this study.

\section{References}

1. Mathuranath PS, Nestor PJ, Berrios GE, Rakowicz W, Hodges
JR. A brief cognitive test battery to differentiate Alzheimer's disease and frontotemporal dementia. Neurology 2000;55:161320 .

2. Morris JC, Heyman A, Mohs RC, Hughes JP, van Belle G, Fillenbaum G, et al. The Consortium to Establish a Registry for Alzheimer's Disease (CERAD). Part I. Clinical and neuropsychological assessment of Alzheimer's disease. Neurology 1989;39:1159-65.

3. Bier JC, Ventura M, Donckels V, Van Eyll E, Claes T, Slama H, et al. Is the Addenbrooke's cognitive examination effective to detect frontotemporal dementia? J Neurol 2004;251:428-31.

4. Bier JC, Donckels V, Van Eyll E, Claes T, Slama H, Fery P, et al. The French Addenbrooke's cognitive examination is effective in detecting dementia in a french-speaking population. Dement Geriatr Cogn Disord 2004;19:15-7.

5. Mathuranath PS, Hodges JR, Mathew R, Cherian PJ, George A, Bak TH. Adaptation of the ACE for a Malayalam speaking population in southern India. Int $J$ Geriatr Psychiatry 2004;19:1188-94.

6. Brodaty H, Moore CM. The Clock Drawing Test for dementia of the Alzheimer's type: A comparison of three scoring methods in a memory disorders clinic. Int J Geriatr Psychiatry 1997;12:619-27.

7. Ganguli M, Ratcliff G, Chandra V, Sharma SD, Gilby JE, Pandav $\mathrm{R}$, et al. A Hindi version of the MMSE: The development of a cognitive screening instrument for a largely illiterate rural elderly population in India. Int J Geriatr Psychiatry 1995;10:367-77.

8. de Silva HA, Gunatilake SB. Mini mental state examination in Sinhalese: A sensitive test to screen for dementia in Sri Lanka. Int J Geriatr Psychiatry 2002;17:134-9.

9. Ganguli M, Chandra V, Gilby JE, Rateliff G, Sharma SD, Pandav $R$, et al. Cognitive test performance in a community-based nondemented elderly sample in rural India: The Indo-U.S. CrossNational Dementia Epidemiology Study. Int Psychogeriatr 1996;8:507-24

10. Chandra V, Ganguli M, Ratcliff G, Pandav R, Sharma S, Belle S, et al. Practical issues in cognitive screening of elderly illiterate populations in developing countries. The Indo-US Cross-National Dementia Epidemiology Study. Aging (Milano) 1998;10:349-57.

11. Director of Census Operations Kerala. District Census Handbook, Trivandrum. Village and Town Directory. Village, Panchayat and Townwise Primary Census Abstract. Tiruvananthapuram. Director of Census Operations: Kerala; 1991

12. Fillenbaum GG, George LK, Blazer DG. Scoring nonresponse on the Mini-Mental State Examination. Psychol Med 1988;18:1021-5.

13. Mathuranath PS, George A, Cherian PJ, Mathew R, Sarma PS Instrumental activities of daily living scale for dementia screening in elderly people. Int Psychogeriatr 2005;17:461-74.

Accepted on 20-03-2007

Source of Support: Mrs. Meera Pattabi (from the Trivandrum Chapter of the Alzheimer's and Related Disorders Society of India: ARDSI), Mr. Radhamoni (from the ARDSI and the Senior Citizen's Forum, Trivandrum), and the office bearers of various Residents Associations in Trivandrum., Conflict of Interest: This study was supported in part by a grant-in-aid from Sir Ratan Tata Trust (SRTT), Mumbai, India, and the Kerala State Council for Science, Technology and Environment (KSCSTE). The sponsors had no role in the research formulation, study design, data collection and analysis or in the decision to publish these results. There is no financial relationship between any of the authors and the sponsors. 